\title{
A Study on Chances of Surgical-site Infection after Orthopedic Surgery with Factors Related to the Hospital
}

\section{Mohsen Hojat ${ }^{1}$, Navid Kalani' ${ }^{1}$, Mojdeh Rahmanian ${ }^{3 *}$}

${ }^{1}$ Department of Nursing, Jahrom Medical University of Medical Sciences, Jahrom, Iran

${ }^{2}$ Research Center for Social Determinants of Health, Jahrom University of Medical Sciences, Jahrom, Iran

${ }^{3}$ Pediatric Nursing Master of Science, Jahrom Medical University of Medical Sciences, Jahrom, Iran

Study Area: Jahrom, Iran

Coordinates: $28^{\circ} 30^{\prime} \mathrm{oo} " \mathrm{~N} ; 53^{\circ} 33^{\prime} 38^{\prime \prime} \mathrm{E}$

Key words: Shavers, Shifts, Wound, Caretakers

\section{Introduction:}

In spite of the fact that tremendous advances have been made in surgical techniques, the pathogeneses of surgical wound infections have been identified and prophylactic antibiotics are in wide use for overcome the surgical-site infection (SSI), with an incidence of about $2-5 \%$ and a $24 \%$ share in-hospital infections. It is considered to be among the major challenges in orthopedic surgeries. Surgical site infections have the second-highest number of nosocomial infections (Favero et al., 1995). SSI can increase the cost of treatment, increase the number of post-operative days of admission, increase absenteeism from the workplace for the family and caregivers, reduce patient satisfaction and deteriorate the patient's condition (Hojat et al., 2013; Taheri et al., 2015). According to CDC, 500,00o cases in the United States each year sustain with surgical site infections. On average, hospitalization period for these patients increases by 7.5 days with the estimated cost of $\$ 845-800$ million (Leaper et al., 2004; PugUese \& Favero, 200o). Several factors including clinical conditions of the patient, prolonged preoperative hospitalization, duration of
Abstract

Apart from failure in the treatment of patients postoperative infections after orthopedic surgery, resulting in the death of patients. The present study designed and carried out for predicting surgical site infection after orthopedic surgery with hospital factors on 420 orthopedics patients who needed surgery. Data were collected by filledup the questionnaire (during the hospitalization period). Using the multivariable logistic regression test with the Enter model, the following variables were able to predict the risk of the surgical wound. The variety of surgical operations, simultaneous orthopedic surgery in operating rooms, can increase the risk of wound infection by 1.317 times more than that of just done orthopedic surgery in the operating rooms. The high average of the mean shift of personnel in a month increases the risk of wound infections by 1.235 times higher than that of normal staff working hours. And most importantly, the need for postoperative dressing more than 1 time during the first 48 hours increases the risk of wound infection by 39.297 times. Conclusively, the reducing staff overtime, reducing the need for postoperative dressings, reducing non-orthopedic surgery in the operating room on orthopedic surgery day can reduce the incidence of orthopedic wound infections.

surgery, prepare the skin, the technique of sterilizing the hands by the surgeon and the surgical team, operating room conditions, the type of prosthesis and so on can affect the post-orthopedic infection (Hojjat et al., 2012). Developing an effective care system is always the first step in dealing with the problem of nosocomial infection. The most important and primary goal of treatment is must be to reduce the amount of infection in the surgical site and thus reduce mortality and discomfort of patients and improve the care of patients. In order to achieve this goal, firstly, the predictive and effective variables in the incidence of surgical infection should be identified. Although various studies have been conducted to evaluate the incidence of post-operative infections in orthopedic patients, the causes of these infections are still open to be examined (Brandt et al., 2008; Yokoyama et al., 2009; Bhuachalla et al., 2015; Kokavec \& Fristáková, 2008; Akbari et al., 2003 ). In addition to doing physical and psychological damage to the patient, the surgical site infection, especially in orthopedic patients, increases the cost of treatment, the bed occupancy rate, the length of hospitalization of the patient, and even

*Corresponding Author: hashemif@sums.ac.ir 
the incidence of complications after orthopedic surgery (Hojat et al., 2010). Identification of effective hospital factors in the development of orthopedic wound infection can be considered as an important alarm for the treatment team (Jahromi et al., 2015).

Therefore, any study that can predict the risk of infection in these patients, predict the predictor factors and have high predictive power can be a good guide for planning to correct, eliminate or reduce the impact of risk factors to prevent orthopedic wound infection. The present study was conducted with the aim of predicting wound infection after orthopedic surgery with hospital factors. .

\section{Methodology:}

This analytic study was conducted in Jahrom University of Medical Sciences in 2013-2011. Total of 420 orthopedics patients who needed surgery was included in this study. Patients who died of severe trauma had previous anemia or weakened the immune system, comportment syndrome, previously had post-operative infections did not tend to participate in the study and patients requiring intensive care before or after surgery were not included in the study. Data was collected by a researcher-making questionnaire (during the hospitalization period) with written consent. The form and content validity of the tool was obtained with the help of 10 university professors (IS:0.89, CVI: 0.93, CVR: 0.85 ) and the reliability of the tool was calculated using the test-retest method (o.83). SPSS16 software was used for data analysis

\section{Result:}

Total $88.6 \%$ of patients were having diploma and other education, lower than a diploma. $85 \%$ of cases shavers were the caregivers, $69.5 \%$ of shaves were performed in the morning shift. $72.9 \%$ of them underwent surgery in the evening shift. $51.4 \%$ of the applied prosthesis was Iranian. $42.6 \%$ received general anesthesia. The average number of admission day'spre-operation 1.39 (.553). Only $26.2 \%$ of the patients were admitted to the surgical ward before surgery. $10.4 \%$ of the patients were transferred from other hospitals before surgery. $97.4 \%$ of the patients were admitted to the surgery ward after the surgery. The average postoperative days were $4.63(3.786)$. Using the multivariable logistic regression test with the Enter model showed the following variables could not predict the incidence of surgical wound infection (Table-1).

Using the multivariable logistic regression test with the Enter model, the following variables were able to predict the risk of the surgical wound. The variety of surgical operations, simultaneous orthopedic surgery in operating rooms, can increase the risk of wound infection by 1.317 times more than that of just done orthopedic surgery in the operating rooms. The high average of the mean shift of personnel in a month increases the risk of wound infections by 1.235 times higher than that of normal staff working hours. Most importantly, the need for postoperative dressing more than 1 time during the first $48 \mathrm{hr}$. increases the risk of wound infection by 39.297 times (Table-2).

$\log ?=-41.975-.118$ variable6-2.147 variable4- .367 variable1+3.671 variable $5+.211$ variable $3+.275$ variablez

Table 1: Variables independent to the incidence of surgical wound infection

\begin{tabular}{|c|c|c|c|c|c|}
\hline & $\begin{array}{l}\text { Unsta } \\
\text { Coeff. }\end{array}$ & ind. & $\begin{array}{l}\text { Stand } \\
\text { Coeff. }\end{array}$ & & \\
\hline Model inter & $\mathrm{B}$ & SE & Beta & $\mathrm{t}$ & Sig. \\
\hline The : & -.005 & .029 & -.007 & -.175 & .861 \\
\hline The education level of sha & -.020 & .011 & -.068 & -1.796 & .073 \\
\hline The shaving shift & .007 & .022 & .015 & .319 & .750 \\
\hline $\begin{array}{l}\text { The mean time between surgery } \\
\text { to discharge }\end{array}$ & .043 & .030 & .069 & 1.439 & .151 \\
\hline $\begin{array}{l}\text { Average time between shaving } \\
\text { to surgery }\end{array}$ & .002 & .007 & .011 & .286 & $\cdot 775$ \\
\hline 'Type & .029 & .021 & .054 & 1.399 & .163 \\
\hline $\begin{array}{l}\text { Day of the w } \\
\text { surgery w }\end{array}$ & .027 & .022 & .047 & 1.198 & .232 \\
\hline Mea & .057 & .022 & .111 & 2.622 & .009 \\
\hline Тyр & .002 & .010 & .010 & .208 & .836 \\
\hline Transfer fror & -.017 & .019 & -.035 & -.908 & .365 \\
\hline Wards befo & .095 & .069 & .053 & 1.378 & .169 \\
\hline $\begin{array}{l}\text {-Antibiotics applied before \& } \\
\text { after surgery }\end{array}$ & .000 & .003 & -.006 & -.086 & .932 \\
\hline Antibic & -.274 & .169 & -.094 & -1.619 & .106 \\
\hline $\begin{array}{l}\text {-Skin ol } \\
\text { opeI }\end{array}$ & .069 & .055 & .068 & 1.261 & .208 \\
\hline ne between shaving & .001 & .001 & .040 & 1.063 & .289 \\
\hline $\begin{array}{l}\text {-Average time between hospitali- } \\
\text { zation to surgery }\end{array}$ & .000 & .009 & -.003 & -.042 & .967 \\
\hline -The shift of su & -.011 & .010 & -.170 & -1.166 & .244 \\
\hline The & .001 & .000 & .074 & 1.873 & .062 \\
\hline $\begin{array}{l}\text {-The mean time of admission } \\
\text { before and after surgery }\end{array}$ & .002 & .004 & .016 & .410 & .682 \\
\hline
\end{tabular}

Table 2: Multivariate logistic regression model for variables affecting surgical site infection

\begin{tabular}{|c|c|c|c|c|c|}
\hline Variables & $\mathrm{B}$ & S.E. & Wald & Sig. & $\operatorname{Exp}(B)$ \\
\hline $\begin{array}{l}\text { - Mean number of operations } \\
\text { performed in the shifts in OR }\end{array}$ & -.367 & .080 & 21.126 & .000 & 693 \\
\hline $\begin{array}{l}\text {-Type of operations done in } \\
\text { the shifts in OR }\end{array}$ & .275 & .091 & 9.157 & .002 & 1.317 \\
\hline $\begin{array}{l}\text { Mean shift of personnel in } \\
\text { a month }\end{array}$ & .211 & .077 & $7 \cdot 467$ & .006 & 1.235 \\
\hline -Infected patients in the room & -2.147 & 1.099 & 3.820 & .051 & .117 \\
\hline $\begin{array}{l}\text { Frequency of postoperative } \\
\text { dressing }\end{array}$ & 3.671 & .707 & 26.939 & .000 & 39.297 \\
\hline - Need to dressing in home & -.118 & .060 & 3.887 & .049 & .889 \\
\hline - Constant & -41.975 & 16.356 & 6.586 & .010 & .000 \\
\hline
\end{tabular}

Discussion:

In this study, none of the variables related to surgical site shaving, such as the person who performs shaving (patient, care givers, nurse), the education level of the person who does the shave, the shift in which shaving is done, the mean time 
interval between shaving and surgery did not relate the incidence of orthopedic wound infection. While Maksimovic's study conducted in Belgrade reported that in patients who were shaved with a razor, the period of 12 or more hours between shaving and intervention was also an independent risk factor (OR, 2.77; 95\% CI, 1.22-6.28) (Maksimovic et al., 2008).In the Guide to the Elimination of Orthopedic Surgical Site Infections published by the Association for Professionals in Infection Control and Epidemiology (APIC), it is announced that the shorter the interval between shaving the surgery site and the operation, the lower the risk of infection with orthopedic wound (Rosenbaum et al., 2010). The mean surgical time was not also an effective predictor in the incidence of surgical site infections. As per Soroush et al. (2007) in Iran, the duration of surgery was introduced as the risk factor for the incidence of surgical wounds. While in the review of Cheng et al. (2017), specifically for orthopedic surgeries, an increase in the mean operative time by $20 \%$ or greater ( 3 h) was reported to be associated with adjusted odds ratios ranging from 3.63 to 7.40. Pooled analyses for orthopedic surgery, irrespective of operative time threshold, demonstrated a statistically significant association, with an increased $84 \%$ likelihood of SSI. Prolonged operative time can increase the risk of SSI. In addition, the study demonstrates comprehensively that prolonged operative time can increase the likelihood of developing SSI across a broad array of surgical procedures and surgical specialties. Overall, pooled analyses demonstrated that patients with extended operative times across a wide range of procedures had approximately twice the likelihood of developing SSI, and on overage, the mean operative time was approximately 30 min longer in patients with SSIs as compared with those patients without SSIs. Nevertheless, given the importance of SSIs on patient outcome and health care economics including hospital reimbursement penalties, hospitals should focus efforts to reduce operative time. Further, contrary to our study, the duration of surgeries longer than 3 hours (OR, 3.633) was reported by Li et al. (2013).

In the study of Ribeiro et al. (2013) among the variables studied by the logistic regression model, only the total time of admission in the hospital could affect the incidence of surgical site infection, while in this study this variable could not have shown such an effect on the incidence of surgical wound infections. They also found that the type of anesthesia was also not effective in the incidence of orthopedic wound infections. In our study, like the study of Ribeiro et al. (2013) and de Boer et al. (1999), the use of prophylaxis antibiotics was not found as a good predictor of the incidence of orthopedic wound infections, even for clean wounds. Nevertheless, Li et al. (2013) reported the use of prophylactic antibiotics as a preventative factor in the incidence of orthopedic wound infection.

Like our study, the variables that could predict the incidence of surgical site infections were far less investigated in other studies. Therefore, there was less possibility to make a comparison with the results of other studies. However, in the case of the variables 1, 2 and 4 listed in Table-1, it can be stated that the increase in the number of operations in a specific shift in the operating room, operations other than orthopedic surgery in the same shifts in the operating room, and the presence of an infected patient in the orthopedic not-infected patient room within the first four days after surgery can increase the risk of surgical wound infections. The APIC Orthopedic Infection Removal Guide states that air quality in the operating room is one of the factors affecting the incidence of orthopedic wound infections.

Traffic Patterns were also considered as another important risk factor, and it was said that studies have also shown that the number of individuals in the operating room and the amount of movement of these individuals within the OR both increase the number of colony-forming units as measured by settle plates within the room. Olsen et al. (2003) reported that two or more residents participating in the operative procedure were an independent risk factor for SSIs in spine surgery. Therefore, it is important that movement of personnel is kept to a minimum while invasive procedures are in progress.

With respect to variable 3 in Table-1, it could be stated that the higher the number of personnel shifts, the greater the incidence of orthopedic wound infection. This issue has been highlighted in different aspects of other studies in nursing management, where the increase in the average number of personnel shifts in each ward can endanger the patient's safety and increase hospital complications. As a result, the number of hospital admission days will be higher, the professional commitment will decrease and job burnout will increase (Hojat et al., 2010, 2012, 2013; Karimyar \& Hojat, 2014). Based on variables 5 \& 6 of Table-1, it could be stated that to minimize the infection, when the more secretions and bleeding from the wound, the more changes in the dressing and would be required in both; in the hospital and at home. Finally, reducing staff overtime, reducing the need for postoperative dressings, reducing non-orthopedic surgery in the operating room on orthopedic surgery day can reduce the incidence of orthopedic wound infections.

\section{Acknowledgment:}

We appreciate to all patients and staff that helped us with this study. The present study was conducted with the financial support of Jahrom University of Medical Sciences (HSR.9o / 6).

\section{References:}

Akbari, M., Hosseini M.S., Yazdani, A., Asadi, S. \& Marashi, A. (2003): Incidence of wound infection in elective patients with or without skin preparation. Iranian J. Urol., 9(36):40-35.

Bhuachalla, C.F.N., Nolan, E., Galvin, D., Buckley, C.M. \& Fitzpatrick, F. (2015): Prevention and management of infection associated with transrectal ultrasound guided prostate biopsy in Ireland. Int. J. Infect. Control, 11(4):15 .

Brandt, C., Hott, U., Sohr, D., Daschner, F., Gastmeier, P. \& Rüden, H.(2008): Operating room ventilation with laminar airflow shows no protective effect on the surgical site infection rate in orthopedic and abdominal surgery. Ann. Surg., 248(5):695- 
700.

Cheng, H., Chen, B.P., Soleas, I.M., Ferko, N.C., Cameron, C.G. \& Hinoul, P. (2017): Prolonged operative duration increases risk of surgical site infections: a systematic review. Surg. Infect., 18(6):722-735.

de Boer, A.S., Mintjes-de Groot, A.J., Severijnen, A.J., van den Berg, J.M. \& van Pelt, W. (1999): Risk assessment for surgical-site infections in orthopedic patients. Infect. Control Hosp. Epidemiol., 20(6):402-407.

Favero, M.S., Gaynes, R.P., Jarvis, W.R., Shaw, J., Tablan, O.C. \& Tenover, F.C. (1995): Recommendations for preventing the spread of vancomycin resistance; recommendations of the Hospital Infection Control Practices Advisory Committee (HICPAC). Infect. Control Hosp. Epidemiol., 16(2):105-113.

Greene, L.R. (2012): Guide to the elimination of orthopedic surgery surgical site infections: an executive summary of the association for professionals in infection control and epidemiology elimination guide. Am. J. Infect. Control, 40(4):384-386.

Hojat, M., Karimyar, J.M, Salehifard, A. \& Keshaei, N. (2013): Assessment the effect of various factors on the incidence of surgical site infection in orthopedic patients. Iranian J. Surg., 21(2):53-6o.

Hojat, M., Mohebi, J., Nazari, V. \& Charkh-Andaz, M. (2010): Personnel and patients satisfaction as a measure of service quality measurement. Iran J. Nursing, 23(65):73-82.

Hojjat, M., Karimyar, J.M., Keshaei, N. \& Salehifard, A. (2012): Assessment of the prevalence of post-operation orthopedic wound infection in the orthopedic ward of Motahari hospital (2009-2010). Iranian J. Surg., 20(2):65-75.

Karimyar, J.M. \& Hojat, M. (2014): Assessing burnout syndrome etiologies and stress tendency in nurses. Pars J. Med. Sci., $12(1): 1-13$.

Kokavec, M. \& Fristáková, M. (2008): Eff icacy of antiseptics in the prevention of post-operative infections of the proximal femur, hip and pelvis regions in orthopedic pediatric patients. Analysis of the first results. Acta Chir. Orthop. Traumatol. Cech., 75(2):106-109.

Leaper, D.J., Van Goor, H., Reilly, J., Petrosillo, N., Geiss, H.K., Torres, A.J. \& Berger, A. (2004): Surgical site infection-a European perspective of incidence and economic burden. $\underline{\text { Int }}$. Wound J., 1(4):247-273.
Li, G-q., Guo, F-f., Ou, Y., Dong, G-w., Zhou, W. (2013): Epidemiology and outcomes of surgical site infections following orthopedic surgery. Am. J. Infect. Control, 41(12):1268-1271.

Maksimovic, J., Markovic-Denic, L., Bumbaširevic, M., Marinkovic, J. \& Vlajinac, H. (2008): Surgical site infections in orthopedic patients: prospective cohort study. Croat. Med. L., 49(1):58-65.

Jahromi, M.K., Sobhanian, S., Hojat, M. \& Taheri, L.(2015): Correlation between hemoglobin levels with wound infections in orthopedic patients: a case-control study. Jokull L., 65(6):186-195.

Olsen, M.A., Mayfield, J., Lauryssen, C., Polish, L.B., Jones, M., Vest, J. \& Fraser, V.J. (2003): Risk factors for surgical site infection in spinal surgery. J. Neurosurg., 98(2S):149-155.

Pugliese, G. \& Favero, M.S. (2000): Nosocomial endocarditis in the ICU. Infection Con. Hosp. Epidemiol., 1(8):138.

Ribeiro, J.C., Santos, C.B.d, Bellusse, G.C., Rezende, V.d.F., \& Galvão, C.M. (2013): Occurrence and risk factors for surgical site infection in orthopedic surgery. Acta Paul. de Enferm., 26(4):353-359.

Rosenbaum, P., Aureden, K., Cloughessy, M., Goss, L., Kassai, M. \& Streed, S. (2010): Association for Professionals in Infection Control and Epidemiology. Washington, DC. 2010. Med. Coun. Iran, 25(4):463-473.

Soroush, A, Makarem, J., Yonesian, M., Fazeli, M.S., Hajabdolbaghi, M. \& Noori, M.(2007): Surgical wound infection and its effective factors in general surgery patients. $J$. Med. Coun. Iran., 25(4):463-473.

Taheri, L., Jahromi, M.K., Hojat, M. (2015): Comparison patients and staffs satisfaction in general versus special wards of hospitals of Jahrom. Global J. Health Sci. , 7(6):5-100.

Yokoyama, K., Itoman, M., Nakamura, K., Uchino, M., Nitta, H. \& Kojima, Y. (2009): New scoring system predicting the occurrence of deep infection in open upper and lower extremity fractures: efficacy in retrospective re-scoring. Arch. Orthop. TraumaSurg.,129(4):469-474. 